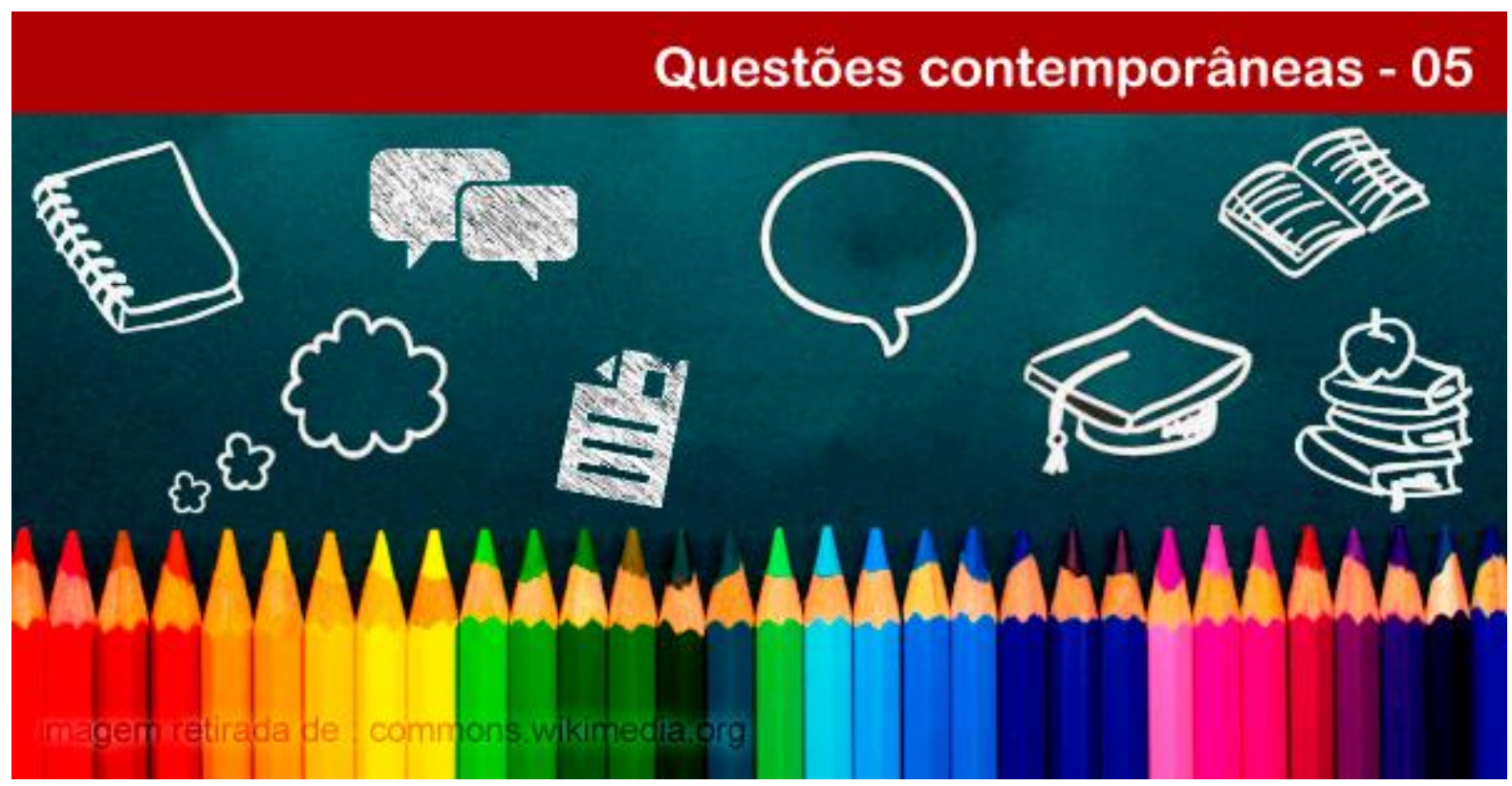

\title{
O CURRÍCULO E A CONSTRUÇÃO DA IDENTIDADE DE GÊNERO DE ALUNOS(AS) DE UM INTERNATO AGRÍCOLA
}

\section{Ana Cláudia da Silva Rodrigues}

Pedagoga. Mestrado e Doutorado em Educação. Professora Adjunta III, vinculada ao Departamento de Educação, Centro de Ciências Humanas, Sociais e Agrárias, Campus III da Universidade Federal da Paraíba (UFPB).E-mail: claudiacavn@yahoo.com.br.

Laise Munique Alves da Silva

Graduanda do curso de Licenciatura em Pedagogia, do Centro de Ciências Humanas, Sociais e Agrárias, Campus III da Universidade Federal da Paraíba (UFPB). E-mail: laise_anjosdanoite@hotmail.com.

\section{Jonantas Soares Hortins}

Aluno do Curso Técnico em Agroindústria, Colégio Agrícola Vidal de Negreiros, vinculado ao Centro de Ciências Humanas, Sociais e Agrárias, Campus III da Universidade Federal da Paraíba (UFPB). E-mail: jonatas-fontelles@hotmail.com.

\section{Tiago José dos Santos}

Aluno do Curso Técnico em Agropecuária, Colégio Agrícola Vidal de Negreiros, vinculado ao Centro de Ciências Humanas, Sociais e Agrárias, Campus III da Universidade Federal da Paraíba (UFPB). E-mail: pontes.tiago2016@gmail.com.

Resumo: Este trabalho teve como objetivo verificar como o currículo dos cursos do Colégio Agrícola Vidal de Negreiros (CAVN) contribuem para a formação da identidade de gênero de seus(as) alunos(as). A abordagem metodológica escolhida foi a pesquisa qualitativa. Os sujeitos que participaram da pesquisa foram 20 alunos(as) dos cursos técnicos de nível médio da referida instituição. O instrumento utilizado para coleta de dados foi a entrevista semiestruturada e os Projetos Políticos Pedagógicos (PPPs) dos cursos técnicos de nível médio. Por questões éticas, os sujeitos que se dispuserem a participar desta investigação tiveram seus nomes verdadeiros mudados por letras e números. Após a realização das entrevistas, estas foram transcritas pelo(as) entrevistadores(as) e em seguida analisadas. A organização da análise, a partir da tabulação das entrevistas, foi disposta em três fases: a pré-análise, a exploração do material e o tratamento dos resultados. Após a análise, foram elaboradas as inferências e a interpretação. Ao término da pesquisa conclui-se que os projetos

\section{POLÊM!CA $\mid$ LABORE (s:}

Polêmica - Revista Eletrônica da Uerj - Rua São Francisco Xavier, 524, $1^{\circ}$ andar

bloco D, sl.1001 • Tels.: +55 21 2334-4088 / 4087 • http://www.e-publicacoes.uerj.br/index.php/polemica/index http://www.labore.uerj.br • laboreuerj@yahoo.com.br 
pedagógicos não apresentam na sua constituição direcionamentos para a discussão sobre a identidade de gênero dos(as) seus(as) alunos(as). No entanto, na narrativa dos(as) alunos(as) estes(as) relataram que durante as aulas alguns professores(as) já abordaram o tema de forma a diminuir o preconceito ainda existente na instituição, que segundo mais de 50\% dos(as) entrevistados(as) já foram vítimas de preconceitos por professores(as), alunos(as) e gestores.

Palavras-chave: Gênero. Currículo. Identidade.

\section{THE CURRICULUM AND THE GENDER IDENTITY CONSTRUCTION ON THE STUDENTS OF AGRICULTURAL TECHNICAL SCHOOL}

Abstract: This study aimed to verify how the curriculum of the Agricultural College courses Vidal Negreiros (CAVN) contribute to the formation of their students gender identity (as). The chosen methodological approach was qualitative research. The subjects participating in the study were 20 students (the) technical courses average level of the institution. The instrument used for data collection was the semistructured interview and Political Projects Pedagogic (PPP) of mid-level technical courses. For ethical reasons, subjects who agreed to participate in this research have had their real names changed by letters and numbers. After the interviews were transcribed by these (the) interviewers (as) and then analyzed. The organization of the analysis, from the tabulation of interviews, was arranged in three phases: pre-analysis, exploration of the material and the processing of results. After analysis were drawn inferences and interpretation. At the end of the research it is concluded that the educational projects do not have in its constitution directions for the discussion of gender identity of (the) his students (as). However, in the narrative of (the) students (as) these (as) reported that during the lessons of some teachers (the) already addressed the issue in order to reduce the still existing prejudice in the institution, which according to more than $50 \%$ of (the) respondents (as) have been victims of prejudice by teachers (the, students (as) and managers.

Keywords: Gender. Curriculum. Identity.

\section{Introdução}

Nos últimos anos as discussões sobre o tema da identidade de gênero e a escola ocupam um espaço nas reflexões de pais, professores, gestores e elaboradores de políticas públicas. E este debate precede a compreensão de como a escola, através de seu currículo, poderá contribuir para que crianças, jovens e adultos possam se constituir enquanto sujeitos de direitos, autônomos e emancipados em condições de exercerem plenamente suas identidades.

Destaca-se que este trabalho discutirá os temas relacionados ao currículo, à construção da identidade, especificamente de gênero, e o espaço escolar. Para isso, se faz necessário uma compreensão de que conceitos serão assumidos e como estes direcionaram as análises dos resultados da pesquisa. Inicialmente, entende-se currículo a partir da definição defendida por Sacristán (2000, p. 15) que afirma,

O currículo representa uma prática, da função socializadora e cultural que determinada instituição tem, que reagrupa em torno dele uma serie de subsistemas ou práticas diversas, entre as quais se encontra a prática pedagógica desenvolvida em instituições escolares que comumente chamamos de ensino.

\section{POLÊM!CA $\mid$ LABORE}


Por isso, pensar o currículo escolar significa materializar em um espaço de tempo definido os anseios e aspirações de uma determinada comunidade com relação aos seus sujeitos, sua cultura, função social e perspectivas de formação de uma sociedade. E estas aspirações nortearão as ações docentes que constituirão o seu fazer pedagógico. Corroborando Pimentel (2007, p. 20) afirma que o currículo,

[...] é, antes de tudo, uma configuração dos modos de vida de habitar o mundo, por isso mesmo não pode ser pensado fora dos limites e possibilidades de sentir, agir e pensar a humana-idade que faz as histórias do presente no solo sempre fértil e fecundo da escola e de todos os espaços em que o viver comum inspira e pratica a educação.

Pimentel (2007), na citação acima, define o currículo para além do ensinar e aprender os conhecimentos acumulados pelas civilizações ao longo dos séculos, imagem constantemente difundida de escola e consequentemente de currículo pelos pensadores mais tradicionais. O novo espaço para o currículo atuar se reveste de "humana-idade", de relações, de sujeitos, que sentem, que pensam e agem, deixando de lado o mecanismo da reprodução e vivenciando as experiências cotidianas de ser no mundo, norteadas pelo contexto social, histórico e cultural de cada indivíduo, para depois partir-se para um conhecimento cientifico mais aprofundado.

De uma forma mais direcionada, esta concepção de currículo "representa um conjunto de práticas que propiciam a produção, a circulação e o consumo de significados no espaço social e que contribuem, intensamente, para a construção das identidades sociais e culturais" (MOREIRA, CANDAU, 2007, p. 28). Passa-se então a compreender que nossas relações em determinados espaços e grupos nos produzem, nos modificam, nos dão sentidos, nos constituem e também a outros. E esta constituição é o que comumente denominamos de identidade. Por isso, a importância de se estudar como as escolas contribuem para a construção destas identidades, através do currículo.

A materialização das ações planejadas pela comunidade escolar para o currículo constituirá o seu Projeto Político Pedagógico (PPP). Para Veiga (1995, p. 2), a elaboração e execução do PPP deverão destacar:

Os fins e objetivos do trabalho pedagógico, buscando a garantia da igualdade de tratamento, do respeito as diferenças, da qualidade do atendimento e da liberdade de expressão; A concepção de criança, jovem e adulto, seu desenvolvimento e aprendizagem; As características da população a ser atendida e da comunidade na qual se insere; $\mathrm{O}$ regime de funcionamento; A descrição do espaço físico, das

\section{POLÊM!CA $\mid$ LABORE}

Polêmica - Revista Eletrônica da Uerj - Rua São Francisco Xavier, 524, $1^{\circ}$ andar

bloco D, sl.1001 • Tels.: +55 21 2334-4088/4087 • http://www.e-publicacoes.uerj.br/index.php/polemica/index

http://www.labore.uerj.br • laboreuerj@yahoo.com.br 
instalações e dos equipamentos; A relação de professores, especificando cargos, funções, habilitação e níveis de formação; Os parâmetros de organização de grupos e relação professor/ aluno; A organização do cotidiano de trabalho com crianças, jovens e adultos; A proposta de articulação da escola com a família e a comunidade; $\mathrm{O}$ processo de avaliação, explicitando suas práticas, instrumentos e registros; $\mathrm{O}$ processo de planejamento geral; Trazer anexos como: a matriz curricular vigente e projetos especiais a serem desenvolvidos.

Observa-se que o PPP de uma escola direciona todas as suas ações e principalmente o fazer pedagógico do docente. Neste documento propõem-se um modelo de sociedade, uma visão de educação, escola, docentes, discentes, a serem seguidos por todos que a compõem. Por isso, a importância da discussão da identidade de gênero nos documentos escolares, a reflexão dos docentes e a elaboração de ações que direcionem uma construção social inclusiva.

A temática da identidade vem ocupando espaço nas discussões da academia, principalmente por ser considerada de grande complexidade, uma vez que repercute questões sociais e individuais. Torna-se praticamente impossível discutir a identidade sem relaciona-la às discussões culturais, visto que a construção identitária ocorre em seu interior. Como também não se pode discutir identidade sem considerar o sujeito como individuo (LOPES, MACEDO, 2011).

Para Giddens (2002), uma questão complexa e problemática que envolve a identidade refere-se à alteração radical que a modernidade promoveu na "natureza da vida cotidiana que afeta os aspectos mais pessoais da nossa existência" (p. 09). Para o autor, o eu não é uma entidade passiva, que sofre influências externas. As auto-identidades, ao serem forjadas, influenciam mudanças sociais e suas consequências e implicações alteram o nosso ser no mundo.

Bauman (2005) nos adverte sobre as transitoriedades das identidades sociais, culturais e sexuais na sociedade moderna. Destaca que se pode construir estas identidades a partir de diversas fontes, disponibilizadas ou não por terceiros, muitas vezes provenientes de nossas escolhas, identidades construídas em movimento. Porém, enfatiza que qualquer tentativa de "solidificar" o que se tornou "líquido" será inócua.

Neste texto, o foco de estudo é a discussão contemporânea sobre a identidade cultural e como esta vem se modificando a partir das transformações das sociedades globalizadas. Destaca-se que o entendimento sobre cultura se estabelece a partir da compreensão desta

\section{POLÊM!CA $\mid$ LABORE}


como um sistema simbólico que promove práticas de significação que produzem significados em sujeitos sociais.

Hall (2002), ao estudar o conceito de identidade cultural na sociedade moderna, distingue três concepções de identidade do ser humano: o sujeito do Iluminismo, baseado na concepção de pessoa humana como um indivíduo centrado, dotado das capacidades de razão, que emergia quando nascia e permanecia o mesmo até a morte; o sujeito sociológico, presente no mundo moderno e que não é independente, uma vez que se forma pela relação que estabelece com os outros que mediavam para ele os valores, sentidos e símbolos, ligando o sujeito à estrutura social; e o sujeito pós-moderno, que apresenta uma identidade fragmentada, composta de várias identidades, às vezes contraditórias ou não resolvidas: "formada e transformada continuamente em relação às formas pelas quais somos representados ou interpelados nos sistemas culturais que nos rodeiam" (HALL, 2002, p. 13).

Castells (2010), ao estudar o poder das identidades culturais nas sociedades contemporâneas, define identidade como:

\footnotetext{
O processo de construção de significado com base em um atributo cultural, ou ainda um conjunto de atributos culturais inter-relacionados, o(os) qual (is) prevalece $(\mathrm{m})$ sobre outras fontes de significado. Para um determinado indivíduo ou um ator coletivo, pode haver identidades múltiplas. No entanto, essa pluralidade é fonte de tensão e contradição tanto na auto-representação quanto na ação social (p. 22).
}

A definição apresentada por Castells (2010) corrobora com a compreensão de currículo como práticas que propiciam a produção de significados, ou seja, produção de identidades. A questão central que, no entanto, deve-se refletir diz "respeito a como, a partir de quê, por quem, e para quê isso acontece" (p. 23). São justamente estas reflexões levantadas pelo autor que ajudarão a discutir o tema da identidade de gênero. Enfatiza-se que as discussões aqui apresentas sobre identidade, gênero e sexualidade, serão trabalhadas a partir da perspectiva dos estudos de Hall (2002), Giddens (2002), Bauman (2005), Louro (2000) e Salih (2015).

Salih (2015), ao analisar a definição de gênero da autora Judith Butler, renomada teórica nos estudos Queer, afirma que o termo significa "um processo que não tem origem nem fim, de modo que é algo que 'fizemos', e não algo que 'somos'” (p. 67). Ou seja, nosso gênero, como nossa identidade, não são natos, mas constituídos à medida que nos

\section{POLÊM!CA $\mid$ LABORE}


posicionamos frente às mais diversas situações, instituições ou grupos sociais. Para Bortolini (2011),

\begin{abstract}
falar de gênero não significa simplesmente falar "de mulher", mas de relações de poder, materiais e simbólicas, que envolvem todos os seres humanos. Significa visibilizar e problematizar os modos de significação dos corpos, dos jeitos de ser, de andar, de falar; questionar os discursos biologizantes que tentam encontrar a essência genética ou hormonal dos comportamentos, assim como o modo como a própria ciência produz discursos normatizadores e reguladores da sexualidade e do gênero (p. 29).
\end{abstract}

Para Louro (2000), a concepção perpassada ao longo da história é que vivemos nossos corpos, universalmente, da mesma forma. "No entanto, podemos entender que a sexualidade envolve rituais, linguagens, fantasias, representações, símbolos, convenções, ou seja, processos profundamente culturais e plurais" (p. 62). No entanto, a escola ao longo do tempo tem repassado conceitos e concepções sobre identidade, gênero e sexualidade que aprisionam e polarizam o ser ou o não ser, a construção da cultura do certo e do errado, do feminino e do masculino. E estas orientações escolares são perpassadas de geração a geração através do currículo, condicionando ações e reverberando preconceitos.

Pensar a sexualidade é também pensar em estruturas de poder que construíram ao longo da história conceitos e preconceitos, que estabeleceram e deram significado culturalmente através do discurso a uma concepção binária de sexo. Butler (2003) utiliza a concepção de performance em que Bortolini (2011) esclarece que

nós não nascemos homens e mulheres, nem simplesmente nos tornamos - num determinado momento - homens e mulheres, mas nos fazemos homens e mulheres todos os dias, quando andamos de um determinado jeito, falamos de uma determinada maneira, usamos determinadas roupas, construímos o nosso corpo de um determinado modo, sempre referenciados a uma norma hegemônica de gênero (p. 29)

É justamente esta norma hegemônica de gênero que a escola referencia, através do discurso imposto socialmente e observado na sua cultura organizacional cotidianamente. Professores, funcionários e gestores perpassam da educação infantil ao ensino superior padrões estabelecidos socialmente, normatizados, que definem o que é belo, feio, aceitável, o que é de menino e o que é de menina, decide o que se deve comer, vestir, falar, ouvir, inclusive e principalmente como se deve viver a sexualidade. Estas normas são construídas e desconstruídas, e envolvem desigualdades, opressões, contradições e enfrentamentos.

\title{
POLÊM!CA $\mid$ LABORE
}


Por isso, esta pesquisa busca compreender as questões sobre identidade de gênero e o currículo a partir das questões abaixo:

Que identidade(s) está(ão) sendo construída(s) ou negada(s) na escola atualmente? Como o currículo, materializado no Projeto Político Pedagógico contribuí para esta construção? Que identidade(s) de gênero(s) perpassam as normativas curriculares? Que ações desenvolvidas pela escola contribuem para a formação da identidade de gênero dos seus alunos(as)? Os(as) alunos(as) internos(as) no CAVN apresentam dificuldades por assumiram sua orientação sexual?

$\mathrm{Na}$ tentativa de responder as questões levantadas elege-se como objetivo geral verificar como o currículo dos cursos técnicos de nível médio do Colégio Agrícola Vidal de Negreiros (CAVN) contribuem para a formação da identidade de gênero de seus alunos(as).

\section{Metodologia}

Com o intuito de atender ao objetivo do trabalho definiu-se como abordagem metodológica a pesquisa qualitativa, uma vez que para Minayo (2001), a pesquisa qualitativa trabalha com o universo de significados, motivos, aspirações, crenças, valores e atitudes.

O local da pesquisa é uma escola técnica de nível médio que oferta educação profissional para jovens e adultos de forma articulada e subsequente nos cursos Técnico em Agropecuária, Agroindústria, Aquicultura e Nutrição. No ano de 2016, o Colégio Agrícola Vidal de Negreiros - CAVN, instituição vinculada à Universidade Federal da Paraíba, localizada no campus III, município de Bananeiras-PB, registra 497 alunos matriculados, sendo 181 alunos(as) internos. Prestam serviços à instituição 72 docentes, 93 servidores técnicos administrativos efetivos e 12 servidores terceirizados, segundo dados da secretaria da instituição.

O instrumento utilizado para coleta de dados foi a entrevista semiestruturada, por ser constituída, segundo Manzini (2004), por um roteiro previamente elaborado, composto em sua maioria por questões abertas, propondo uma interação melhor entre o entrevistador e o entrevistado.

Os procedimentos utilizados para as entrevistas foram organizados em dois momentos: 1. Sensibilização - inicialmente os autores passaram de sala em sala esclarecendo aos(as) alunos(as) sobre a pesquisa, seus objetivos, natureza e dados que pretendiam coletar,

\section{POLÊM!CA $\mid$ LABORE}


informando da necessidade de participação espontânea e convidando os(as) que desejassem serem ouvidos(as) com relação ao tema, marcando data e local para realização das entrevistas; 2. Coleta de dados: em dia e hora previamente informados os autores da pesquisa aguardaram os(as) alunos(as). De posse de um roteiro de entrevista foram realizadas as entrevistas. Compareceram ao local 20 alunos(as) dos cursos técnicos de nível médio do CAVN.

Utilizou-se também como instrumento de pesquisa a análise dos Projetos Políticos Pedagógicos (PPPs) dos cursos técnicos de nível médio do Colégio Agrícola Vidal de Negreiros para verificar se os mesmos apresentavam em seus textos direcionamentos para a discussão do tema identidade de gênero. Durante a fase de análise documental observou-se as orientações de Flick (2009), que enfatiza a necessidade de se questionar "quem produziu o documento e com que objetivos" (p. 234-235) considerando-os como uma "versão específica de realidades construídas para objetivos específicos" (FLICK, 2009, p. 234), contextualizando as informações advindas da pesquisa. Foram analisados os PPPs dos cursos técnicos de nível médio em: Agropecuária, Agroindústria, Aquicultura e Nutrição e Dietética.

A organização da análise, a partir da tabulação das entrevistas, foi disposta em três fases: a primeira, a pré-análise, que busca tornar operacionais e sistematizar as ideias iniciais conduzindo a um plano de análise, levando em consideração as escolhas dos documentos que atendessem a regra da exaustividade e a regra da pertinência; a segunda, a exploração do material se consistiu na codificação e categorização. A terceira fase aborda o tratamento dos resultados, a inferência e a interpretação (Bardin, 2011). Assim estabeleceram-se as seguintes categorias de análise: escolha do local de estudo, abordagem do tema em sala de aula e atitudes homofóbicas sofridas na instituição. Após a realização das entrevistas estas foram transcritas pelo entrevistador e em seguida analisadas. Destaca-se que, por questões éticas, os sujeitos que se dispuserem a participar desta investigação tiveram seus nomes verdadeiros mudados por letras e números

\section{Resultados e discussão}

Inicia-se apresentando o resultado da entrevista realizada com os(as) alunos(as) sobre questões relativas ao tema gênero, sexualidade e currículo.

Escolha do local de estudo

\section{POLÊM!CA $\mid$ LABORE}


A primeira questão levantada refere-se aos motivos que os levaram a optar por estudar na instituição. Dos(as) 20 alunos(as) entrevistados(as), 5 afirmaram que a principal finalidade foi o desejo de sair de casa e obter a tão sonhada liberdade. Outros 5 relataram que os cursos ofertados pela instituição foi o que mais motivou.

Ao serem indagados se suas expectativas foram atendidas, $60 \%$ dos entrevistados relataram que sim e $40 \%$ que não. Observe abaixo os principais argumentos:

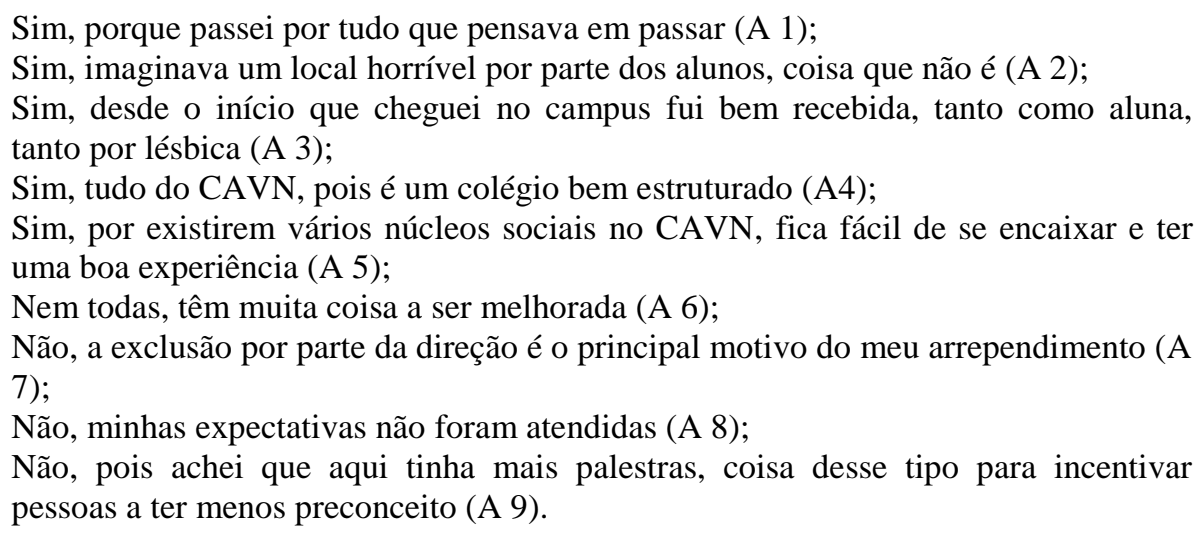

Como observado, os que afirmaram que as expectativas foram atendidas, atribuíram principalmente à infraestrutura da instituição. Esta constatação é verídica, uma vez que por ser uma instituição federal e que oferta internato, o CAVN dispõem de vários espaços e serviços que contribuem para a formação humana dos(as) seus(uas) alunos(as). No entanto, também é relevante destacar que para $40 \%$ dos(as) entrevistados(as) suas expectativas não foram atendidas. Para o(a) aluno(a) identificado como "A9", inclusive, não foram registradas no CAVN palestras sobre o tema da identidade de gênero e a sexualidade, afirmando inclusive, que esta ação poderia contribuir para a diminuição do preconceito.

Interessante a constatação realizada pelo(a) entrevistado(a) identificado(a) por “A9”, que esperava um outro currículo nesta instituição, relatando que o motivo de não atendimento de suas expectativas foi justamente a falta de atenção demonstrada na ausência de palestras sobre o tema para diminuir o preconceito. Louro (2000) enfatiza que estamos no meio de uma disputa em torno das identidades sexuais travada cotidianamente, em múltiplas instâncias sociais, e a escola como espaço que contribui para a constituição de sujeitos não pode se omitir neste processo.

A escola e mais precisamente o currículo vivenciam disputas de interesses contraditórios, por um lado o discurso hegemônico imposto que remete a uma única

\section{POLÊM!CA $\mid$ LABORE (}

Polêmica - Revista Eletrônica da Uerj - Rua São Francisco Xavier, 524, $1^{\circ}$ andar

bloco D, sl.1001 • Tels.: +55 21 2334-4088 / 4087 • http://www.e-publicacoes.uerj.br/index.php/polemica/index http://www.labore.uerj.br • laboreuerj@yahoo.com.br 
construção identitária possível, que seria "à norma branca, masculina, heterossexual e cristã. De outro lado grupos sociais não hegemônicos lutam para se fazer ouvir, rompendo o silenciamento a que foram historicamente submetidos" (LOURO, 2000, p. 56).

A inserção destes sujeitos no espaço escolar desta instituição instiga, desconcerta, incomoda, impulsiona, inquieta, transforma. A escola não pode mais silenciar, uma vez que este silenciamento em torno das "novas" identidades sexuais contribuiria para a marginalização, para o preconceito, a homofobia. O silêncio seria a tomada de posição por um lado, o da omissão. Cercear o direito que estes(as) jovens tem de se expressarem e reivindicarem seu espaço social enquanto sujeitos de direitos é contribuir para a exclusão. O currículo com isto deve ser revisto, reorganizado, redescoberto, contextualizado para possibilitar que estes(as) alunos(as) tenham "o direito de se representar a si mesmo, dizer de si, afirmar a sua cultura, sua linguagem, sua estética" (LOURO, 2000, p.56).

\section{$\underline{\text { Abordagem do tema em sala de aula }}$}

Solicitou-se que os entrevistados(as) informassem se já presenciaram a discussão em sala sobre o tema identidade de gênero. Os(as) alunos(as) em sua maioria informaram que não presenciaram a discussão sobre o tema na sua sala, porém para 5 entrevistados(as) uma docente do componente curricular de Geografia tem tentado discutir o tema e colaborado para a diminuição do preconceito existente.

Destaca-se, no entanto, que existem 72 docentes, no ano de 2016, que ministram aulas no CAVN e que ao registrarem que apenas uma docente apresentou o tema em sala, os(as) entrevistados(as) demonstram a ausência de discussões sobre a temática por aqueles que conduzem o processo ensino aprendizagem na instituição. Porém, não se pode culpabilizar os docentes por não contribuírem com a inclusão de tais discussões em seus componentes, uma vez que a abordagem da identidade de gênero ainda está em fase inicial de construção.

Os temas sexualidade e construção de sujeitos e de relações entre sujeitos dotados de corpos sempre estiveram presentes na escola, contudo como forma de disciplinamento, normatização e heteronormatividade de corpos. No discurso dos docentes da educação infantil, do ensino médio e até na educação superior o que se presenciava era a grande preocupação com o ajustamento social dos alunos às normas hegemonicamente estabelecidas e entre elas estavam a afirmação da existência, apenas, do sexo feminino e masculino como

\section{POLÊM!CA $\mid$ LABORE}


possível. Só a partir de 2006, depois de muita luta dos movimentos que defendem a causa LGBT, teremos através da promulgação do Plano Nacional de Educação em Direitos Humanos, uma orientação para a discussão na educação básica sobre os temas,

[...] fomentar a inclusão, no currículo escolar, das temáticas relativas a gênero, identidade de gênero, raça e etnia, religião, orientação sexual, pessoas com deficiências, entre outros, bem como todas as formas de discriminação e violações de direitos, assegurando a formação continuada dos(as) trabalhadores(as) da educação para lidar criticamente com esses temas (BRASIL/CNDH/MEC, 2006, p. 24)

Portanto, se faz necessário ainda formações continuadas para que docentes possam discutir de forma inclusiva e sem preconceitos a temática nas escolas públicas. Principalmente se levarmos em consideração que o local da pesquisa é uma instituição com vocação agrária que oferta, há mais de 90 anos, um ensino para a formação de profissionais de nível médio para o mercado de trabalho. Ressaltando, principalmente, que estes docentes são formados em sua maioria em cursos de bacharelado, sem aproximação com a área das ciências humanas.

No entanto, faz-se necessário também uma discussão curricular mais efetiva na instituição. Visto que é na elaboração dos Projetos Políticos Pedagógicos (PPPs) que a comunidade escolar, formada por docentes, discentes, gestores, representantes de pais e a comunidade externa, se posicionam quanto ao direcionamento que a instituição dará as suas ações. Discutir o currículo significa pensar, primeiramente, no sujeito que se pretende formar, para que sociedade, com quais características, dentro de que contextos. Isto é dar sentido ao currículo.

Para Lopes e Macedo (2011), “o currículo é uma prática de significação, de atribuição de sentidos. Ele constrói a realidade, nos governa, constrange nosso comportamento, projeta nossa identidade, tudo isso produzindo sentidos" (p. 41). Por isso, pensar o currículo e sua materialização através do PPP é promover uma interseção entre projetos sociais distintos, produzidos por sujeitos distintos, que estão envoltos em relações de poder. Portanto, o currículo é uma prática de poder. Escolher o que ensinar, como ensinar e para quê ensinar se reveste de significados, que contribui para manter ou alterar estruturas sociais estabelecidas. Assim sendo, as discussões sobre identidades devem fazer parte do currículo, contribuindo para produções de significados e para a legitimação de grupos sociais minoritários.

\section{Atitudes homofóbicas sofridas na instituição}

\section{POLÊM!CA $\mid$ LABORE}


Na próxima questão solicitou-se que os(as) entrevistados(as) relatassem se já sofreram algum tipo de preconceito relacionado a sua identidade de gênero. Dos entrevistados, 6 responderam que sim, 4 falaram que não e 10 não responderam. Seguem, abaixo, os relatos

Sim, por guardas do campus, em meio a uma discussão fui vítima de uma frase irônica falada pelo mesmo. (A2)

Sim, funcionários que não aceitam, ignoram chegando até xingar e nos desrespeitam. (A5)

Por uma professora que me chamou de "viadinho". (A7)

Sim, quantidades de pães no RU, gay não pode pegar mais de um pão, mulher pode, funcionários soltando piadas. (A8)

Dentre as narrativas destacaremos duas para análise. Não por serem as outras desmerecedoras de reflexão, mas apenas por entendermos que elas estão contidas nas formas de preconceitos abordadas pelas demais. A primeira diz respeito ao termo pejorativo proferido pela professora. Ora, ao se discutir o preconceito existente na sociedade, vários autores decorreram sobre seus malefícios para as relações sociais e humanas, para o convívio social. Autores como Bandeira e Batista (2002) vão mais longe e discutem o preconceito como expressões de violência. Para os autores,

Pela sua sutileza, caráter difuso e capilaridade de intromissão nas relações sociais, a
eficácia e a ubiquidade do preconceito são máximas, tanto em relação as práticas de
controle, como as de dominação e subordinação em todas as categorias sociais.
Manifestam-se como produtor e reprodutor de situações de controle, menosprezo,
humilhação, desqualificação, intimidação, discriminação, fracasso e exclusão nas
relações entre os gêneros, na esfera do trabalho, nas posições de poder, nos espaços
morais e éticos e nos lugares de enunciação da linguagem (p. 127).

Por isso, a nossa surpresa ao nos deparamos com a situação vivenciada pelo aluno (A7), descrita acima. Como não nos perguntarmos sobre o lugar que a escola, através dos seus professores, representa para a formação do aluno? Se o local de construção e reconstrução identitária passa a representar a violência, a opressão, a discriminação e o preconceito, que jovens e adultos teremos? Se um professor demonstra uma intolerância tamanha que não identifica seu aluno pelo nome civil, e sim pelo termo "viadinho", que sociedade estamos construindo? Nesta situação não temos a violência real, mas a psicológica. O objetivo é atingir o sujeito, no mais profundo do seu ser. É menosprezá-lo. É humilhá-lo. É impor, através do professor representante da sociedade dominante, o local do dominado, através do discurso. É subjugá-lo.

\section{POLÊM!CA $\mid$ LABORË}


O segundo relato é ainda mais chocante: "gay não pode pegar mais de um pão" (A8). A escola, através de sua cultura organizacional, cria e recria suas próprias regras e isto é de conhecimento de todos que a compõem, mesmo sem ser oficial, perpassa a cultura dos seus membros. Por isso, o que o aluno narra é muito grave, principalmente por envolver um espaço público de oferta de alimentos para seus alunos internos. A possibilidade de ter negado o alimento é uma violência real. É a negação de um direito vital, o de alimentar-se. Choca-nos saber que jovens em formação, que além de enfrentarem no seu dia a dia muitas formas de violência pela sociedade, vão presenciar, na escola, a negação de sua existência.

Tal realidade apresentada pelos alunos tem impacto direto na autoestima e no rendimento escolar desses jovens. Por isso, precisamos sair da lei do silêncio. Precisamos discutir e debater os temas sobre a identidade de gênero e orientação sexual na escola. Na questão seguinte, ao indagarmos sobre ações desenvolvidas pelo CAVN que levem em consideração os temas citados anteriormente, os alunos informaram que não existem. Sabemos que o preconceito e a violência contra a comunidade LGBT não é exclusiva da escola, porém se esta não der o primeiro passo para termos uma sociedade mais justa e inclusiva continuaremos a propagar a violência e a presenciar tais atos no nosso cotidiano.

O segundo instrumento de pesquisa escolhido para apresentar os dados necessários para atender ao nosso objetivo foi a análise documental. Os documentos analisados foram os Projetos Políticos Pedagógicos (PPPs) dos cursos Técnico de Nível Médio em Agropecuária, Agroindústria, Aquicultura e Nutrição do CAVN.

Para a análise documental elaborou-se um roteiro com o intuito de verificar se os referidos projetos apresentam na sua constituição fundamentos que abordem os temas da inclusão e da diversidade para em seguida, se fossem encontrados, verificar se os referidos temas incluíam as discussões sobre identidade de gênero e orientação sexual. Observou-se nos documentos que estes foram organizados nos últimos cinco anos, por docentes, coordenadores de curso e por gestores da instituição. Foram aprovados nos colegiados instituídos e estão em fase de avaliação e estabelecimento de novos direcionamentos, com comissões legalmente constituídas para realização das modificações necessárias. Enfatiza-se que o mais recente documento implementado foi o PPP do curso técnico em Nutrição e Dietética, produzido e aprovado no ano de 2014. Após leitura dos PPPs, destaca-se que não foram encontrados

\section{POLÊM!CA $\mid$ LABORE}


fundamentos, nem temas que fizessem alusão à inclusão, diversidade, identidade de gênero e orientação sexual.

Os PPPs analisados apresentam na sua organização todos os itens referentes à formação necessária a um profissional técnico da área. Porém, a escola esquece que os profissionais são sujeitos em formação e precisam, em seus ambientes de trabalho, aprender a conviver. Por isso, orienta-se que a revisão destes projetos pedagógicos proporcione a inclusão de ações implementadas para que a escola possa cumprir sua função de preparar as futuras gerações para a vida.

Inserir a discussão de gênero na escola e em seu currículo torna-se então necessário, pois a escola como organização viva está dentro de questões temporais e atemporais, e não pode negar a existência, permanência e resistência de situações que envolvem o ser humano que ali está sendo formado (re)produzindo habitus (BOURDIEU, 1983b) e preconceitos que excluem e violentam muitos cotidianamente.

Trabalhar as relações de gênero implica em muito mais que esclarecer o que a dominação de um gênero sobre o outro pode causar, como também a naturalidade da violência atribuída entre meninos e meninas e a quem não se encaixa em padrões estabelecidos pelo padrão de heteronormatividade construída socialmente, desse modo avaliamos que é preciso direcionar atenção para o que está sendo feito enquanto currículo flexível (plano de ensino) e que o currículo oculto seja aferido pelo educador ou por funcionários que estão na instituição escolar.

A escola é responsável pela manutenção de bem-estar e segurança de todos os seus alunos, em vista disto não pode negar que não haja conflitualidades com as relações de gênero, o que ela faz com tais conflitualidades é o que não pode passar despercebido, pois a cultura é um organismo vivo e pode ser modificada, para isto se faz necessário rever em seu currículo suas relações com crenças, ideologia, pressupostos e ações que corroboram para que cidadãos estão formando.

Quando se fala em violência de gênero, não se pensa apenas em poder opressor de homem contra mulher, mas de poder masculino construído sobre o que é feminino, efeminado. $\mathrm{O}$ que atinge toda uma comunidade, de gays, lésbicas, bissexuais, transexuais e travestis, e todos estes sujeitos estão na escola, pertencem e fazem parte do currículo, mesmo que silenciosamente, violentados ou cerceados por ele.

\section{POLÊM!CA $\mid$ LABORE}


O currículo tem intencionalidades, seja de transformar ou conservar valores de quem a domina. Conscientizar-se sobre os malefícios que tais ideologias podem ocasionar é finalmente criar possiblidades de uma escola inclusiva e sem aspas, é dar voz e direitos aos sujeitos que se encontram rodeados de estigmas, daí a atenção pedagógica para a desconstrução de modelos hegemônicos e construção de um currículo com valores baseados em ações afirmativas, com novos valores e novas práticas nas relações escolares.

\section{Conclusão}

Ao término da pesquisa conclui-se que os Projetos Políticos Pedagógicos dos cursos Técnicos de Nível Médio do CAVN não apresentam na sua organização direcionamentos para a discussão sobre a identidade de gênero dos(as) seus alunos(as). Observa-se uma densa organização, em cada curso, de um perfil profissional que atenda às demandas da sociedade atual em cada área. No entanto, não se admite uma formação profissional distante das questões que orientam a vida e a sociedade. Pensar no profissional para o mercado de trabalho é prepará-lo para conviver em um espaço constituído por sujeitos de direitos que devem exercer plenamente suas identidades.

Enfatiza-se que na narrativa dos(as) alunos(as), estes(as) relataram que durante as aulas alguns professores(as) já abordaram o tema sobre a identidade de gênero contribuindo para a diminuição do preconceito ainda existente na instituição, que segundo mais de 50\% dos(as) entrevistados(as) já foram vítimas. E que este preconceito é demonstrado por alguns professores(as), alunos(as) e funcionários(as).

\section{Referências}

BAUMAN, Zygmunt. Identidade. (Tradução Carlos Alberto Medeiros). Rio de Janeiro: Jorge Zahar Editor, 2005.

BARDIN, Laurence. Análise de conteúdo. São Paulo: Edições 70, 2011.

BANDEIRA, Lourdes; BATISTA, Anália Soria. Preconceitos e descriminações como expressões de violência. Estudos feministas, ano 10, primeiro semestre, p. 120-141, 2002.

BORTOLINI, Alexandre. Diversidade Sexual e de Gênero na Escola. Revista Espaço Acadêmico, n.123, agosto 2011.

BRASIL. Comitê Nacional de Educação em Direitos Humanos. Plano Nacional de Educação em Direitos Humanos. Brasília: Secretaria Especial dos Direitos Humanos, Ministério da Educação, Ministério da Justiça, 2006.

\section{POLÊM!CA LABORE}


BUTLER, Judith. Problema de Gênero: feminismo e subversão da identidade. Rio de Janeiro: Civilização Brasileira, 2003.

BOURDIEU. Pierre. Sociologia (Organizado por Renato Ortiz). São Paulo: Ática, 1983.

CASTELLS, Manuel. O poder da identidade - A era da informação: economia, sociedade e cultura. (Tradução Klauss Brandini Gerhardt). V. 2. São Paulo: Editora Paz e Terra, 2010.

FLICK, Uwe. Introdução à pesquisa qualitativa. (Tradução Joice Elias Costa). $3^{\text {a }}$. Ed. - Porto Alegre: Artmed, 2009.

GIDDENS, Anthony. Modernidade e identidade. (Tradução Plínio Dentzien). Rio de Janeiro: Jorge Zahar, 2002.

HALL, Stuart. A identidade cultural na pós-modernidade. (Tradução Tomaz Tadeu da Silva e Guacira Lopes Louro). $7^{\circ}$ ed. Rio de Janeiro. DP\&A, 2002.

LOPES, Alice Cassimiro; MACEDO, Elizabeth. Teorias de Currículo. São Paulo: Cortez, 2011.

LOURO, Guacira Lopes. Currículo, Gênero e Sexualidade. Portugal: Porto Editora, 2000.

MANZINI, Eduardo Jose. Entrevista semiestruturada: análise de objetivos e de roteiros. Disponível em: <http://www.sepq.org.br/IIsipeq/anais/pdf/gt3/04.pdf>. Acesso em: 3 jun. 2015.

MINAYO, Maria Cecília de Souza (Org.). Pesquisa social: teoria, método e criatividade. Petrópolis: Vozes, 2001.

MOREIRA, Antonio Flávio Barbosa; CANDAU, Vera Maria. Currículo, conhecimento e cultura. In: Beauchamp, J.; Pagel, S. D.; Nascimento, A. R. Indagações sobre currículo: currículo, conhecimento e cultura. Brasília: Ministério da Educação, Secretaria de Educação Básica. 2007. p. 17-46. Disponível em: 〈http://portal.mec.gov.br/seb/arquivos/pdf/Ensfund/indag3.pdf>. Acesso em: 13 jun. 2016.

PIMENTEL, Álamo. Prefácio. In: MACEDO, Roberto Sidnei. Currículo, Diversidade e Equidade: luzes para uma educação intercrítica. Salvador: Edufba, 2007.

SACRISTAN, J. Gimeno. O Currículo, uma reflexão sobre a prática. Porto Alegre: Editora Artmed, 2000.

SALIH, Sara. Judith Butler e a teoria Queer. (Tradução Guacira Lopes Louro). $1^{\mathrm{a}}$. Ed.; $2^{\mathrm{a}}$. Reimpr. Belo Horizonte: Autentica Editora, 2015.

VEIGA, IIma Passos Alencastro (Org.). Projeto Político Pedagógico da Escola: uma construção possível. Campinas: Papiros, 1995.

Recebido em: 20/07/2016.

Aceito em: 29/09/2016.

\section{POLÊM!CA $\mid$ LABORE}

Polêmica - Revista Eletrônica da Uerj - Rua São Francisco Xavier, 524, $1^{\circ}$ andar

bloco D, sl.1001 • Tels.: +55 21 2334-4088 / 4087 • http://www.e-publicacoes.uerj.br/index.php/polemica/index

http://www.labore.uerj.br • laboreuerj@yahoo.com.br 